\title{
SURVEILLANCE OF HEMODIALYSIS RELATED INFECTIONS: A PROSPECTIVE MULTICENTER STUDY, FIRST REPORT FROM TURKEY
}

Imran Hasanoğlu¹, Rahmet Güner ${ }^{1}$, Hacı Veli Atalay ${ }^{2}$, Suzan Şahin ${ }^{3}$, Ergün Parmaksız ${ }^{3}$, FATMA YILMAZ KARADAĞ ${ }^{4}$, Sabahat Alısır Ecder ${ }^{5}$, Tugba Arslan Gülen ${ }^{6}$, Zuhal Atan Uçar $^{6}$, Oğuz Karabay ${ }^{7}$, Savaş Sipahi ${ }^{7}$, Esra Kaya Kılıç ${ }^{8}$, Murat Duranay ${ }^{8}$, Derya Yapar $^{9}$, İbrahim Doğan ${ }^{10}$, Gülden Ersöz ${ }^{11}$, Gülcan Türkmen ${ }^{12}$, and Ahmet Alper Kıykım ${ }^{13}$

${ }^{1}$ Ankara Yildirim Beyazit University Faculty of Medicine

${ }^{2}$ Ankara Gülhane Ĕ̈itim ve Araştırma Hastanesi

${ }^{3}$ Istanbul Dr Lütfi Kırdar Kartal Eğitim ve Araştırma Hastanesi

${ }^{4}$ Affiliation not available

${ }^{5}$ Medeniyet University Goztepe Training and Research Hospital

${ }^{6}$ Niğde Ömer Halisdemir University

${ }^{7}$ Sakarya Universitesi Tip Fakultesi

${ }^{8}$ Sağlık Bakanlı̆̆ı Ankara Eŭitim ve Araştırma Hastanesi

${ }^{9}$ Hitit University Faculty of Medicine,Turkey.

${ }^{10}$ Hitit University

${ }^{11}$ Mersin Üniversitesi Tıp Fakültesi

${ }^{12}$ Mersin Universitesi

${ }^{13}$ Mersin University

November 12, 2020

\begin{abstract}
Background There is neither a surveillance system nor a study to reveal the HD related infection rates in Turkey. We aimed to investigate the infection rate among HD outpatients and implement CDC's surveillance system. Methods A multicenter prospective surveillance study is performed to investigate the infection rate among HD patients. CDC National Healthcare Safety Network dialysis event (DE) protocol is adopted for definitions and reporting. Results During April 2016-April 2018, 9 centers reported data. A total of 199 DEs reported in 10035 patient-months, and the overall DE rate was 1.98 per 100 patient-months. Risk of blood culture positivity is found to be 17.6 times higher when hemodialysis was through a tunneled catheter than through an arteriovenous fistula. DE rate was significantly lower in patients educated about the care of their vascular access site. Mean body mass index was significantly higher in patients with any DE. Staphylococcus aureus was the most causative microorganism among mortal patients. Outcomes of DEs were hospitalization (73\%), loss of vascular access $(18.2 \%)$, and death $(7.7 \%)$. Conclusions This first surveillance study in Turkey gave insight into current DE status and will guide to generate a national surveillance system for maintaining much lower DE rates.
\end{abstract}

\section{Hosted file}

trhies-manuscript-short version-static.pdf available at https://authorea.com/users/ 375177/articles/492518-surveillance-of-hemodialysis-related-infections-a-prospective- 
multicenter-study-first-report-from-turkey

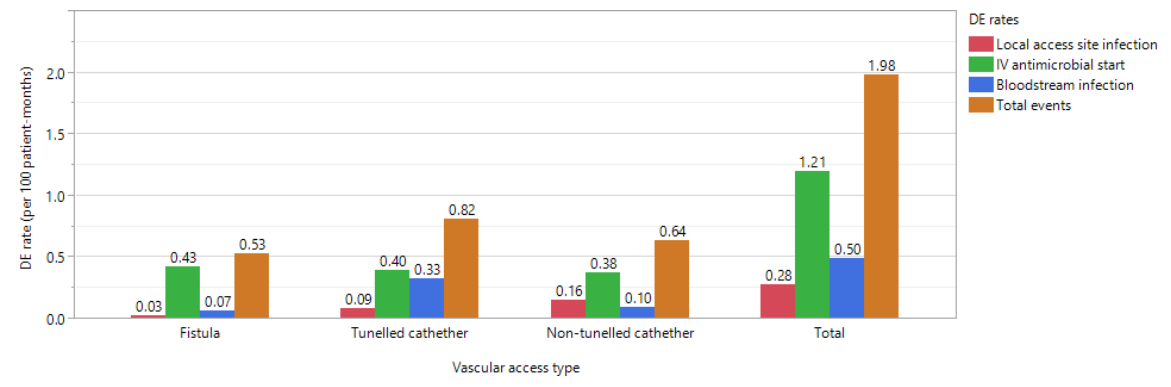

